Susanne Petersen

Frauen in der

Französischen Revolution 
Für Tina \& Lena Dank an Rositta \& Walther 


\section{Susanne Petersen}

\section{Frauen in der Französischen Revolution}

Dokumente - Kommentare - Bilder

Akademie-Verlag Berlin 1987 
Verkauf nur in der

Deutschen Demokratıschen Republik

und in den anderen sozialistıschen Ländern gestattet

ISBN 3-05-000614-5

Lizenzausgabe des Pahl-Rugensteın Verlags GmbH, 5000 Köln 51

Lizenznummer. 202 100/176/87

Gestaltung. Willi Hölzel/Andreas Tsordanıdıs

LSV 0235

Bestellnummer 7548612 (9098)

01680 